\title{
Anti-dementia Activity of Nobiletin, a Citrus Flavonoid: A Review of Animal Studies
}

\author{
Akira Nakajima', Yasushi Ohizumi ${ }^{2,3,4,5}$, Kiyofumi Yamada ${ }^{1}$ \\ 'Department of Neuropsychopharmacology and Hospital Pharmacy, Graduate School of Medicine, Nagoya University, Nagoya, ${ }^{2}$ Department \\ of Molecular Toxicology, School of Pharmaceutical Sciences, University of Shizuoka, Shizuoka, ${ }^{3}$ Department of Anti-Dementia Functional \\ Food Development, Research Center of Supercritical Fluid Technology, Graduate School of Engineering, Tohoku University, Sendai, \\ ${ }^{4}$ Laboratory of Kampo Medicines, Yokohama College of Pharmacy, Yokohama, ${ }^{5}$ Kansei Fukushi Research Institute, Tohoku Fukushi \\ University, Sendai, Japan
}

\begin{abstract}
Alzheimer's disease $(\mathrm{AD})$, the most common form of dementia among the elderly, is characterized by the progressive decline of cognitive function and has a detrimental impact worldwide. Despite intensive laboratory and clinical research over the last three decades, pharmacological options for the prevention and effective long-term treatment of AD are not currently available. Consequently, successful therapeutic and preventive treatments for $A D$ are needed. When researching materials from natural resources having anti-dementia drug activity, we identified nobiletin, a polymethoxylated flavone from the peel of Citrus depressa. Nobiletin exhibited memory-improving effects in various animal models of dementia and exerted a wide range of beneficial effects against pathological features of $A D$ including amyloid $-\beta(A \beta)$ pathology, tau hyperphosphorylation, oxidative stress, cholinergic neurodegeneration and dysfunction of synaptic plasticity-related signaling, suggesting this natural compound could become a novel drug for the treatment and prevention of $A D$.
\end{abstract}

KEY WORDS: Nobiletin; Alzheimer's disease; Memory; Amyloid $\beta$; Hyperphosphorylated tau; Oxidative stress; Cholinergic neurodegeneration.

\section{INTRODUCTION}

Alzheimer's disease (AD), the most common form of dementia among the elderly, is characterized by the progressive decline of cognitive function and has a detrimental impact globally. The number of AD cases worldwide was estimated at 36 million in 2010 and is predicted to triple by $2050{ }^{1)}$ The pathological hallmarks of $\mathrm{AD}$ are amyloid- $\beta$ (A $\beta$ ) plaques and neurofibrillary tangles (NFT) accompanied by neurodegeneration, loss of synapses and failure of neurotransmitter pathways, partic-

\footnotetext{
Received: February 4, 2014 / Revised: February 23, 2014

Accepted: March 31, 2014

Address for correspondence: Kiyofumi Yamada, PhD

Department of Neuropsychopharmacology and Hospital Pharmacy,

Graduate School of Medicine, Nagoya University, 65 Tsuruma-cho,

Showa-ku, Nagoya 466-8560, Japan

Tel: +81-52-744-2674, Fax: +81-52-744-2876

E-mail: kyamada@med.nagoya-u.ac.jp

Yasushi Ohizumi, PhD

Kansei Fukushi Research Institute, Tohoku Fukushi University,

6-149-1 Kunimigaoka, Aoba-ku, Sendai 989-3201, Japan

Tel: +81-22-728-6009

E-mail: ohizumi@tfu-mail.tfu.ac.jp
}

ularly those of the cholinergic system. Currently, two classes of drugs are approved for the treatment of $\mathrm{AD}^{2-4)}$ One is acetylcholinesterase (AChE) inhibitors, such as donepezil, galantamine and rivastigmine, which increase the neurotransmitter acetylcholine levels in the synapses. The other is a noncompetitive $N$-methyl-D-aspartate (NMDA) receptor antagonist, memantine, which exerts its neuroprotective effect by inhibiting glutamate-mediated excitotoxicity. These drugs can help alleviate the cognitive symptoms of $\mathrm{AD}$ patients but do not prevent, halt, or reverse the disease progression. ${ }^{3,4)}$ Consequently, despite intensive laboratory and clinical research over the last three decades, pharmacological options for the prevention and effective long-term treatment of AD are not available currently and, thus, are needed.

Many compounds from natural resources have become promising candidates for drug development, ${ }^{5)}$ as well as pharmacologically useful. ${ }^{6}$ When evaluating materials from natural resources having anti-dementia drug activity, we identified nobiletin, a polymethoxylated flavone from the peel of Citrus depressa (Fig. 1). Nobiletin enhances protein kinase A (PKA)/extracellular signal-regulated

(c) This is an Open-Access article distributed under the terms of the Creative Commons Attribution Non-Commercial License (http://creativecommons.org/licenses/by-nc/3.0) which permits unrestricted non-commercial use, distribution, and reproduction in any medium, provided the original work is properly cited. 
kinase (ERK)/cAMP response element-binding protein (CREB) signaling in PC12D cells and cultured rat hippocampal neurons. ${ }^{7,8)}$ In addition, nobiletin induces longterm potentiation (LTP) via activating PKA-dependent phosphorylation of the alpha-amino-3-hydroxy-5-methyl-4-isoxazolepropionic acid (AMPA) receptor subunit GluR1 in hippocampus slices. ${ }^{9)}$ Furthermore, nobiletin exhibited memory-improving effects in various animal models of dementia, as shown in Table 1. In this article, we summarized recent findings on potential efficacies of nobiletin against $\mathrm{AD}$ by targeting multiple pathological changes of this disease.

\section{MAIN SUBJECTS}

\section{Effects of Nobiletin on Olfactory Bulbectomy-induced} Memory Impairment and Cholinergic Neurodegeneration

The cholinergic system, which plays a significant role in memory function, is seriously impaired in $\mathrm{AD}{ }^{10,11)}$<smiles>COc1ccc(-c2cc(=O)c3c(OC)c(OC)c(OC)c(OC)c3o2)cc1OC</smiles>

Since olfactory bulbectomy (OBX) animals exhibit impaired learning and memory caused by degeneration of the cholinergic system in the central nervous system, ${ }^{12,13)}$ they have been widely utilized as a useful paradigm that shares several major clinical features of AD. ${ }^{14)}$ In addition, marked impairment of olfactory function has been reported at the early stage of AD. ${ }^{15,16)}$ By using OBX mice, the beneficial effects of nobiletin on cognitive impairment as well as cholinergic neurodegeneration were examined by Nakajima et al. ${ }^{17)}$ and Nagase et al. ${ }^{7)}$ In those studies, nobiletin $(50 \mathrm{mg} / \mathrm{kg}$, intraperitoneal [i.p.], or $50-100$ $\mathrm{mg} / \mathrm{kg}$, oral [p.o.]) was administered for 11 days from postoperative day three. In the passive avoidance test, daily administration of nobiletin $(50 \mathrm{mg} / \mathrm{kg}$, i.p., or $50-100$ $\mathrm{mg} / \mathrm{kg}$, p.o.) for 11 days significantly improved OBX-induced associative memory impairment. ${ }^{7,17)}$ Furthermore, short-term memory impairment in the Y-maze test was also improved by treatment with $50 \mathrm{mg} / \mathrm{kg}$ nobiletin (p.o.) for 11 days. ${ }^{7)}$ After completion of the behavioral test, Nakajima et al. ${ }^{17)}$ evaluated the density of AChE staining in the brain to examine the effects of nobiletin on cholinergic neurodegeneration. Eleven-day i.p. administration of nobiletin rescued the OBX-induced decrease in the density of AChE-positive fibers in the hippocampus by $19-32 \%$. Because the intensity of AChE staining reflects the density of cholinergic septohippocampal innervation in the hippocampus ${ }^{18)}$ and behavioral improvement is correlated with recovery of cholinergic markers, such as AChE and choline acetyltransferase, ${ }^{19)}$ the results indicate nobiletin improves impaired memory in OBX mice by protecting cholinergic innervation in their hippocampus.

Fig. 1. Chemical structure of nobiletin.

Table 1. Beneficial effects of nobiletin on memory impairment in animal models of dementia

\begin{tabular}{|c|c|c|c|c|}
\hline Animal models & Behavioral analyses & Vehicle & + Nobiletin & References \\
\hline \multirow[t]{2}{*}{ OBX mice } & Associative memory in the passive avoidance test & $\downarrow$ & Improvement & \multirow[t]{2}{*}{$(7,17)$} \\
\hline & Short-term memory in the Y-maze test & $\downarrow$ & Improvement & \\
\hline A $\beta$-infused rats & Reference and working memory in the radial maze test & $\downarrow$ & Improvement & $(24)$ \\
\hline \multirow[t]{2}{*}{ APP Tg mice } & Context-dependent fear memory in the fear conditioning test & $\downarrow$ & Improvement & \multirow[t]{2}{*}{$(25)$} \\
\hline & Ambulation and rearing in the open-field test & $\downarrow$ & No effect & \\
\hline \multirow[t]{2}{*}{ MK-801-treated mice } & Associative memory in the passive avoidance test & $\downarrow$ & Improvement & \multirow[t]{2}{*}{ (34) } \\
\hline & Context-dependent fear memory in the fear conditioning test & $\downarrow$ & Improvement & \\
\hline \multirow[t]{3}{*}{ Ischemic mice } & Associative memory in the passive avoidance test & $\downarrow$ & Improvement & \multirow[t]{3}{*}{ (39) } \\
\hline & Short-term memory in the Y-maze test & $\downarrow$ & Improvement & \\
\hline & Ambulation in the open-field test & \pm & No effect & \\
\hline \multirow[t]{4}{*}{ SAMP8 mice } & Context-dependent fear memory in the fear conditioning test & $\downarrow$ & Improvement & \multirow[t]{4}{*}{$(43)$} \\
\hline & Tone-dependent fear memory in the fear conditioning test & \pm & No effect & \\
\hline & Recognition memory in the novel object recognition test & $\downarrow$ & Improvement & \\
\hline & Anxiety in the elevated plus maze test & \pm & No effect & \\
\hline
\end{tabular}




\section{Effects of Nobiletin on Memory Impairment in A $\beta$-infused Rats}

Based on the amyloid hypothesis, ${ }^{20)}$ proposing that production and accumulation of $\mathrm{A} \beta$ are central to the pathogenesis of $\mathrm{AD}, \mathrm{A} \beta$-infused rats are widely used as an $\mathrm{AD}$ model. ${ }^{21)}$ Several studies have demonstrated that acute injection or continuous infusion of $\mathrm{A} \beta$ into the brain causes brain dysfunction, as evidenced by neurodegeneration and learning and memory deficits. ${ }^{21-23)}$ Matsuzaki et al. ${ }^{24)}$ examined the effects of nobiletin on the impairment of reference and working memory in $\mathrm{AD}$ rat models produced by chronic infusion of $A \beta_{1-40}$ into the cerebral ventricle using an osmotic pump. Nobiletin (10-50 mg/kg, i.p.) was administered daily to $\mathrm{A} \beta$-infused rats for seven days before and after surgery. In the eight-arm radial maze test, analyses of the effect of the infusion of $\mathrm{A} \beta_{1-40}$ using randomized two-factor (block and group) analysis of variance (ANOVA) showed significant main effects of both blocks of trials and groups on the number of reference memory errors and working memory errors, demonstrating that infusion of $\mathrm{A} \beta_{1-40}$ into the cerebral ventricle causes impairment of reference and working memory in rats. The administration of nobiletin improved both reference and working memory impairment in $\mathrm{A} \beta$-infused rats, suggesting protective ability against $\mathrm{A} \beta$-induced memory deterioration.

\section{Effects of Nobiletin on Memory Impairment and $\mathrm{A} \beta$ Pathology in Amyloid Precursor Protein Transgenic Mice}

Amyloid precursor protein transgenic (APP Tg) mice expressing various mutations identified from patients with familial AD have proven highly valuable in AD-related research. $^{21)}$ Onozuka et al. $^{25)}$ utilized aged APPSwedish/London (SL) 7-5 Tg mice that overexpress human APP695 harboring the double SL mutations as a model to evaluate the beneficial effects of nobiletin on AD pathology. APP-SL 7-5 Tg mice exhibited a small number of $A \beta$ plaques in the hippocampus and entorhinal cortex at the age of 9 months and displayed a considerable number of A $\beta$ plaques at the age of 12 months and older. ${ }^{26)}$ Furthermore, the AD model mice displayed spatial memory deficits as revealed by the Morris Water Maze test performed at ages from 3-12 months. ${ }^{26)}$ Since APP-SL 7-5 Tg mice began to exhibit a small number of $\mathrm{A} \beta$ plaques at 9 months of age, nobiletin $(10 \mathrm{mg} / \mathrm{kg}$, i.p. $)$ was administered daily for 4 months to 9-month-old APP-SL 7-5 Tg mice in Onozuka's study and the effects on memory impairment and A $\beta$ pathology were examined. Treatment with nobi- letin significantly reversed the memory impairments in APP-SL 7-5 Tg mice in the context-dependent fear conditioning test without affecting general behavior. Enzyme-linked immunosorbent assay (ELISA) also showed administration of nobiletin markedly reduced the quantity of guanidine-soluble $\mathrm{A} \beta_{1-40}$ and $\mathrm{A} \beta_{1-42}$ in the brain. Furthermore, consistent with the ELISA results, immunohistochemistry with anti-A $\beta$ antibody showed the administration of nobiletin decreased the $\mathrm{A} \beta$ burden and plaques in the APP-SL 7-5 Tg mice hippocampi. These results suggest nobiletin not only improved the cognitive deficit but also prevented A $\beta$ pathology in a transgenic AD mouse model.

\section{Effects of Nobiletin on MK-801-induced Memory Impairment}

Involvement of NMDA receptor hypofunction has been suggested in brain dysfunction due to aging. Reportedly, the cognitive impairment in aging is associated with reduced NMDA receptor expression. ${ }^{27,28)}$ Furthermore, NMDA receptor hypofunction may be related to the progression of mild cognitive impairment to $\mathrm{AD}$ in the aging brain. ${ }^{29)}$ The mRNA and protein levels of NR1/NR2B subunits were found to be reduced with increasing $A D$ pathological severity in the postmortem brain tissue of AD patients. $^{30)}$ In addition, NMDA receptor subunits were selectively and differentially reduced in areas of the brain in AD patients, and the abnormalities correlated with cognitive AD deficits. ${ }^{31,32)}$ Furthermore, a previous study showed the application of $\mathrm{A} \beta$ promoted the endocytosis of NMDA receptors in cultured neurons, accompanied by persistent depression of NMDA-evoked currents, suggesting prolonged depression of NMDA receptor-mediated transmission may be involved in the initiation of the pathological changes observed in $\mathrm{AD} .^{33)}$

Accordingly, to clarify the effects of nobiletin on cognitive impairment associated with NMDA receptor hypofunction, Nakajima et al. ${ }^{34)}$ examined the effects of nobiletin on learning and memory impairment induced by treatment with MK-801, a noncompetitive NMDA receptor antagonist in mice. In that study, nobiletin (10-50 $\mathrm{mg} / \mathrm{kg}$ i.p.) was injected once daily for seven consecutive days before training for the contextual fear conditioning or passive avoidance test. In the contextual fear conditioning test, treatment with nobiletin $(10-50 \mathrm{mg} / \mathrm{kg})$ dose-dependently reversed the MK-801-induced impairment of context-dependent fear memory by $40-70 \%$. Consistently, in the passive avoidance test, treatment with $50 \mathrm{mg} / \mathrm{kg}$ nobiletin reversed the MK-801-induced associative memory 
deficits by $90 \%$. Since a single passive avoidance training event was previously shown to activate hippocampal ERK, which is necessary for consolidation of resultant learning, ${ }^{35,36)}$ the effects of nobiletin on MK-801-induced inhibition of hippocampal ERK activation after the passive avoidance training in mice were examined. Notably, repeated administration of nobiletin completely reversed the MK-801-induced inhibition of hippocampal ERK activation, which was observed in vehicle-treated control animals immediately after the passive avoidance training. Furthermore, nobiletin reversed the MK-801-induced impairment of NMDA-stimulated phosphorylation of ERK in cultured rat hippocampal neurons. These results suggest nobiletin reverses MK-801-induced memory deficits by the activation of ERK signaling in the hippocampus and may provide a new insight into therapeutic drug development for neurological disorders associated with NMDA receptor hypofunction, such as AD.

\section{Effects of Nobiletin on Ischemia-induced Memory Impairment}

Previous studies suggested neurovascular dysfunction is an integral part of $\mathrm{AD} .^{37)}$ Cerebral blood flow (CBF) reductions caused decreased neural activities and blood-brain barrier (BBB) dysfunction in patients with AD. ${ }^{37)}$ Accordingly, studies using animal models indicated $\mathrm{CBF}$ reductions can induce neuropathological changes resembling AD pathology. For example, arterial carotid occlusion was shown to cause memory impairment, synaptic changes and accumulation of $\mathrm{A} \beta$ oligomers in rats. ${ }^{38)}$ Yamamoto et al. ${ }^{39)}$ addressed the issue of whether nobiletin has neuroprotective effects on ischemia-induced neuronal death in the hippocampus, as well as whether it improves the cerebral ischemia-induced memory deficits in a mouse model with bilateral common carotid artery occlusion (BCCAO). Treatment with 50 $\mathrm{mg} / \mathrm{kg}$ nobiletin (i.p.) for seven consecutive days before and after brain ischemia significantly improved 5-min BCCAO-induced associative memory impairment in the passive avoidance test. Similarly, nobiletin treatment improved short-term memory impairment in the Y-maze test. In the 5-min ischemic mice, Western blot analysis showed the levels of synaptic proteins, including calcium/calmodulin-dependent protein kinase II (CaMKII), microtubule-associated protein 2 (MAP2) and GluR1 were significantly decreased in the hippocampal CA1 region. The nobiletin treatment prevented the reduction of CaMKII, MAP2 and GluR1 protein levels in the hippocampal CA1 region, accompanied by restoration of both ERK and
CREB phosphorylation and CaMKII autophosphorylation. Consistent with restored CaMKII and ERK phosphorylation, an electrophysiological study showed the impaired hippocampal LTP observed in the 5-min ischemic mice was significantly improved by nobiletin treatment. These results suggest nobiletin improved ischemia-induced memory deficits, at least in part, by activating CaMKII and ERK signaling.

\section{Effects of Nobiletin on Memory Impairment, Oxidative Stress and Hyperphosphorylation of Tau in Senescence-accelerated Mouse}

Senescence-accelerated mouse (SAM) is a model of accelerated senescence that was established through phenotypic selection from a common genetic pool of AKR/J mice. $^{40)}$ Senescence-accelerated mouse prone (SAMP) has a shortened lifespan and early manifestations of various signs of senescence, whereas senescence-accelerated resistant mouse (SAMR) shows normal aging. The SAMP8 substrain, one of the SAMP strains, has proven to be a relevant model for AD because it shows the early onset of learning and memory deficits and various pathological features of $\mathrm{AD}$ including increased oxidative stress, tau hyperphosphorylation and amyloid plaques. $^{21,41,42)}$ We recently reported the beneficial effects of nobiletin on age-related cognitive impairment as well as

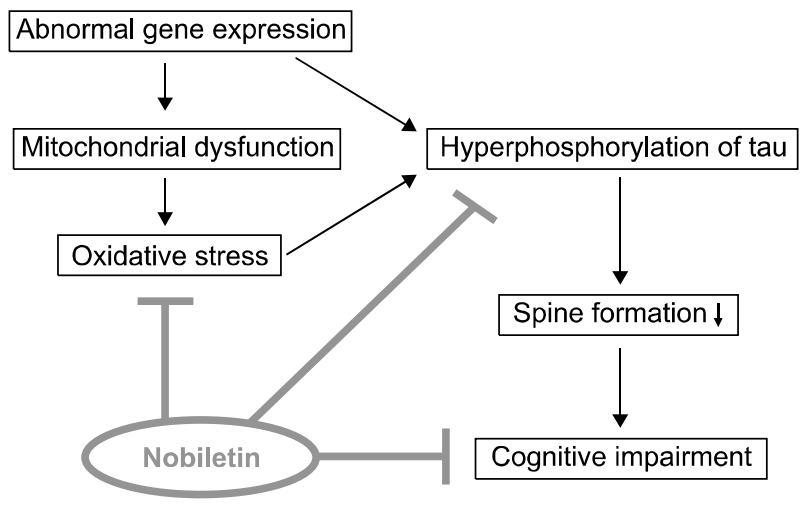

Fig. 2. Beneficial activities of nobiletin in senescence-accelerated mouse prone 8 (SAMP8). In SAMP8 mice, abnormal gene expression may induce mitochondrial dysfunction and oxidative stress with age. Furthermore, tau hyperphosphorylation may lead to deficits in the formation of dendritic spines and neural networks, resulting in cognitive impairment in SAMP8. Treatment with nobiletin significantly decreased protein carbonyl levels, an index of protein oxidation and tau phosphorylation in the brain of SAMP8 mice, which was associated with the restoration of decreased GSH/GSSG ratio as well as increased glutathione peroxidase (GPx) activity. These results suggest nobiletin improves cognitive impairment in SAMP8 mice, at least in part, by reducing oxidative stress and tau hyperphosphorylation. 
pathological features of AD such as oxidative stress and tau hyperphosphorylation in SAMP8 mice. ${ }^{43)}$ Beneficial activities of nobiletin in SAMP8 mice are summarized in Fig. 2.

Reportedly, SAMP8 mice show learning and memory impairment at a young age in several learning and memory paradigms. ${ }^{40)}$ In our study, the novel object recognition test and fear conditioning were employed to examine the effects of nobiletin on age-related cognitive impairment in SAMP8 mice. Nobiletin $(10-50 \mathrm{mg} / \mathrm{kg}$, i.p.) was administered daily for one month to SAMP8 mice aged 4-6 months prior to behavioral experiments. In the novel object recognition test, treatment with nobiletin significantly improved the impairment of object recognition memory in SAMP8 mice. Furthermore, in the fear conditioning test, nobiletin reversed the context-dependent fear memory impairment, which is hippocampus-dependent ${ }^{44)}$ in SAMP8 mice. Tone-dependent fear memory, which is hippocampus-independent, ${ }^{44)}$ was not significantly impaired in SAMP8 mice, consistent with previous reports. ${ }^{45,46)}$ Because evidence has suggested performance in learning and memory tasks could be confounded by emotional state, ${ }^{47,48)}$ we examined the effects of nobiletin on anxiety-like behavior in SAMP8 mice. The animals showed a trend toward reduced anxiety-like behavior in the elevated-plus maze task, although the difference was not statistically significant. Nobiletin had no effect on this anxiety-like behavior in SAMP8 mice, suggesting nobiletin-induced improvement of cognitive impairment in these mice may not be due to altered emotional state. ${ }^{43)}$

Oxidative stress is a major factor in the aging process and in the course of various diseases associated with aging, such as $\mathrm{AD} .^{49)}$ The levels of lipid hydroperoxide and protein carbonyl in the brain of SAMP8 mice were shown to increase with age and are higher than in SAMR1 mice at a younger age. ${ }^{50-52)}$ In our study, we found nobiletin significantly modulated cellular antioxidant defense systems such as the GSH system and antioxidant enzymes in the brain of SAMP8 mice. We showed that treatment with nobiletin restored the decrease in the GSH/GSSG ratio in SAMP8 mice. In addition, nobiletin significantly increased the activity of glutathione peroxidase (GPx), an intracellular antioxidant enzyme that converts peroxides into nontoxic forms, in SAMP8 mice. Consistent with these changes in the antioxidant defense systems, treatment with nobiletin significantly decreased the level of protein carbonyl, an index of protein oxidation, in SAMP8 mice. Given that oxidative stress is related to the development of learning and memory impairment in SAMP8 mice, ${ }^{42)}$ nobiletin potentially improves cognitive impairment in SAMP8 mice, at least in part, by reducing oxidative stress through modulation of endogenous antioxidant defense systems in the brain. Accordingly, recent in vitro studies also showed the antioxidant properties of nobiletin. ${ }^{53-56)}$

In addition to oxidative stress, overproduction of $\mathrm{A} \beta$ and hyperphosphorylated tau, key pathological features of $\mathrm{AD},{ }^{57)}$ is observed in the hippocampus of SAMP8 mice. ${ }^{42)}$ Although $\mathrm{A} \beta_{1-42}$ levels did not increase in the hippocampus of SAMP8 mice at the age of 5-7 months based on Western blotting, we found increased tau phosphorylation levels at Ser202 and Thr231. Notably, treatment with nobiletin reversed the increase in tau phosphorylation at these sites in the hippocampus of SAMP8 mice. Hyperphosphorylation impairs the microtubule binding function of tau, resulting in disorganized microtubule cytoskeleton and blocked axonal transport, leading to retrograde neurodegeneration. ${ }^{58,59)}$ Regarding tau phosphorylation at Ser202 and Thr231, the phosphorylation at Ser202 reportedly inhibits the microtubule assembly-promoting activity of tau, ${ }^{60)}$ and phosphorylation at Thr231 is important in tau binding to microtubules. ${ }^{61)}$ Moreover, phosphorylated tau at these sites has been found in the AD-affected brain. ${ }^{62-64)}$ Taken together, our results with previous reports showing tau pathology is highly reflective of cognitive decline in $\mathrm{AD},{ }^{65-67)}$ indicate nobiletin may be an effective treatment targeting phosphorylated tau and leading to cognitive improvement.

\section{CONCLUSION}

Herein, we provided an overview of potential anti-AD properties of nobiletin. As shown in Table 1, nobiletin exhibits memory-improving effects in various animal models of dementia and exerts a wide range of beneficial effects against pathological features of $\mathrm{AD}$ including $\mathrm{A} \beta$ pathology, tau hyperphosphorylation, oxidative stress, cholinergic neurodegeneration and dysfunction of synaptic plasticity-related signaling. Furthermore, nobiletin has shown anti-neuroinflammatory effects in lipopolysaccharide-stimulated BV-2 microglial cell culture models. ${ }^{68)}$ Collectively, these results suggest this natural compound can become a novel drug for the treatment and prevention of $\mathrm{AD}$.

Bioavailability in the brain is important for drugs to be effective in the treatment of $\mathrm{AD}$ because an inability to cross the BBB could limit the therapeutic applications of drugs. ${ }^{69)}$ Notably, analyses using high-performance liquid 
chromatography (HPLC) and positron emission tomography (PET) suggest nobiletin penetrates the $\mathrm{BBB}$ and reaches a maximal level within 3-5 min after peripheral administration. ${ }^{70,71)}$ Additionally, 4'-demethylnobiletin, a major urinary metabolite of nobiletin in rats and mice, ${ }^{72,73)}$ can cross the BBB and exert memory-improving effects in the brain. $^{74)}$

Although the beneficial pharmacological properties of nobiletin against $\mathrm{AD}$ have been clearly demonstrated in various animal models, primary molecular targets are still unclear. Accordingly, to understand fully the mechanisms of nobiletin action, the primary molecular targets should be determined using advanced target identification techniques, such as chemical proteomic-based approaches. ${ }^{75,76)}$ Furthermore, clinical trials in patients with $\mathrm{AD}$ and/or mild cognitive impairment are necessary to determine if nobiletin exhibits the therapeutic efficacy demonstrated in the animal models of dementia described in this review. Notably, a recent pilot clinical study suggested the possibility that 1-year treatment with nobiletin-rich $C$. reticulata peel extract could prevent progression of the cognitive impairment in donepezil-preadministered AD patients with no adverse side effects. ${ }^{77)}$ Nevertheless, further clinical trials are needed to establish the efficacy of nobiletin as a useful strategy for the prevention and treatment of cognitive decline in patients with $\mathrm{AD}$ and/or mild cognitive impairment.

\section{- Acknowledgments}

This work was supported in part by Grants for Project Research (Development of Fundamental Technology for Analysis and Evaluation of Functional Agricultural Products and Functional Foods) from the Ministry of Agriculture, Forestry, and Fisheries of Japan, Grants for Strategic Research Program for Brain Sciences from the Ministry of Education, Culture, Sports, Science and Technology of Japan, Grants-in-aid for Scientific Research 22390046, 23659135, 23790290, and 24111518 from the Japan Society for the Promotion of Science, a grant from the Smoking Research Foundation, and a grant from the Brain Research Center from the 21st Century Frontier Research Program (2012k001115) funded by the Ministry of Science and Technology, Republic of Korea.

\section{REFERENCES}

1. Wimo A, Prince M. World Alzheimer Report 2010: the global economic impact of dementia. Alzheimer's Disease International 2010:1-56.

2. Cummings JL. Alzheimer's disease. N Engl J Med 2004; 351:56-67.

3. Osborn GG, Saunders AV. Current treatments for patients with Alzheimer disease. J Am Osteopath Assoc 2010;110(9 Suppl 8):S16-S26.

4. Huang Y, Mucke L. Alzheimer mechanisms and therapeutic strategies. Cell 2012;148:1204-1222.

5. Li JW, Vederas JC. Drug discovery and natural products: end of an era or an endless frontier? Science 2009;325: 161-165.

6. Ohizumi Y. Application of physiologically active substances isolated from natural resources to pharmacological studies. Jpn J Pharmacol 1997;73:263-289.

7. Nagase H, Omae N, Omori A, Nakagawasai O, Tadano T, Yokosuka A, et al. Nobiletin and its related flavonoids with CRE-dependent transcription-stimulating and neuritegenic activities. Biochem Biophys Res Commun 2005;337:13301336.

8. Nagase H, Yamakuni T, Matsuzaki K, Maruyama Y, Kasahara J, Hinohara Y, et al. Mechanism of neurotrophic action of nobiletin in PC12D cells. Biochemistry 2005;44: 13683-13691.

9. Matsuzaki K, Miyazaki K, Sakai S, Yawo H, Nakata N, Moriguchi S, et al. Nobiletin, a citrus flavonoid with neurotrophic action, augments protein kinase A-mediated phosphorylation of the AMPA receptor subunit, GluRl, and the postsynaptic receptor response to glutamate in murine hippocampus. Eur J Pharmacol 2008;578:194-200.

10. Auld DS, Kornecook TJ, Bastianetto S, Quirion R. Alzheimer's disease and the basal forebrain cholinergic system: relations to beta-amyloid peptides, cognition, and treatment strategies. Prog Neurobiol 2002;68:209-245.

11. Schliebs R, Arendt T. The cholinergic system in aging and neuronal degeneration. Behav Brain Res 2011;221:555-563.

12. Hozumi S, Nakagawasai O, Tan-No K, Niijima F, Yamadera F, Murata A, et al. Characteristics of changes in cholinergic function and impairment of learning and memory-related behavior induced by olfactory bulbectomy. Behav Brain Res 2003;138:9-15.

13. Yamamoto T, Jin J, Watanabe S. Characteristics of memory dysfunction in olfactory bulbectomized rats and the effects of cholinergic drugs. Behav Brain Res 1997;83:57-62.

14. Bobkova NV, Garbuz DG, Nesterova I, Medvinskaya N, Samokhin A, Alexandrova I, et al. Therapeutic effect of exogenous hsp70 in mouse models of Alzheimer's disease. J Alzheimers Dis 2014;38:425-435.

15. Peters JM, Hummel T, Kratzsch T, Lötsch J, Skarke C, Frölich L. Olfactory function in mild cognitive impairment and Alzheimer's disease: an investigation using psychophysical and electrophysiological techniques. Am J Psychiatry 2003;160:1995-2002.

16. Djordjevic J, Jones-Gotman M, De Sousa K, Chertkow H. Olfaction in patients with mild cognitive impairment and Alzheimer's disease. Neurobiol Aging 2008;29:693-706.

17. Nakajima A, Yamakuni T, Haraguchi M, Omae N, Song SY, Kato C, et al. Nobiletin, a citrus flavonoid that improves memory impairment, rescues bulbectomy-induced cholinergic neurodegeneration in mice. J Pharmacol Sci 2007;105: 122-126.

18. Heckers S, Ohtake T, Wiley RG, Lappi DA, Geula C, Mesulam MM. Complete and selective cholinergic denervation of rat neocortex and hippocampus but not amygdala by an immunotoxin against the p75 NGF receptor. J Neurosci 1994;14:1271-1289.

19. Tarricone BJ, Simon JR, Low WC. Intrahippocampal transplants of septal cholinergic neurons: choline acetyltransferase activity, muscarinic receptor binding, and spatial memory function. Brain Res 1993;632:41-47. 
20. Hardy J, Selkoe DJ. The amyloid hypothesis of Alzheimer's disease: progress and problems on the road to therapeutics. Science 2002;297:353-356.

21. Van Dam D, De Deyn PP. Animal models in the drug discovery pipeline for Alzheimer's disease. Br J Pharmacol 2011;164:1285-1300.

22. Nitta A, Itoh A, Hasegawa T, Nabeshima T. beta-Amyloid protein-induced Alzheimer's disease animal model. Neurosci Lett 1994;170:63-66.

23. Yamada K, Tanaka T, Zou LB, Senzaki K, Yano K, Osada $\mathrm{T}$, et al. Long-term deprivation of oestrogens by ovariectomy potentiates beta-amyloid-induced working memory deficits in rats. Br J Pharmacol 1999;128:419-427.

24. Matsuzaki K, Yamakuni T, Hashimoto M, Haque AM, Shido O, Mimaki Y, et al. Nobiletin restoring beta-amyloidimpaired CREB phosphorylation rescues memory deterioration in Alzheimer's disease model rats. Neurosci Lett 2006;400:230-234.

25. Onozuka H, Nakajima A, Matsuzaki K, Shin RW, Ogino K, Saigusa D, et al. Nobiletin, a citrus flavonoid, improves memory impairment and Abeta pathology in a transgenic mouse model of Alzheimer's disease. J Pharmacol Exp Ther 2008;326:739-744.

26. Shin RW, Ogino K, Shimabuku A, Taki T, Nakashima H, Ishihara $\mathrm{T}$, et al. Amyloid precursor protein cytoplasmic domain with phospho-Thr668 accumulates in Alzheimer's disease and its transgenic models: a role to mediate interaction of Abeta and tau. Acta Neuropathol 2007;113: 627-636.

27. Das SR, Magnusson KR. Changes in expression of splice cassettes of NMDA receptor GluN1 subunits within the frontal lobe and memory in mice during aging. Behav Brain Res 2011;222:122-133.

28. Brim BL, Haskell R, Awedikian R, Ellinwood NM, Jin L, Kumar A, et al. Memory in aged mice is rescued by enhanced expression of the GluN2B subunit of the NMDA receptor. Behav Brain Res 2013;238:211-226.

29. Huang YJ, Lin CH, Lane HY, Tsai GE. NMDA neurotransmission dysfunction in behavioral and psychological symptoms of Alzheimer's disease. Curr Neuropharmacol 2012;10:272-285.

30. Mishizen-Eberz AJ, Rissman RA, Carter TL, Ikonomovic $\mathrm{MD}$, Wolfe BB, Armstrong DM. Biochemical and molecular studies of $N M D A$ receptor subunits NR1/2A/2B in hippocampal subregions throughout progression of Alzheimer's disease pathology. Neurobiol Dis 2004;15:80-92.

31. Sze C, Bi H, Kleinschmidt-DeMasters BK, Filley CM, Martin LJ. N-Methyl-D-aspartate receptor subunit proteins and their phosphorylation status are altered selectively in Alzheimer's disease. J Neurol Sci 2001;182:151-159.

32. Procter AW, Wong EH, Stratmann GC, Lowe SL, Bowen DM. Reduced glycine stimulation of [3H]MK-801 binding in Alzheimer's disease. J Neurochem 1989;53:698-704.

33. Snyder EM, Nong Y, Almeida CG, Paul S, Moran T, Choi $\mathrm{EY}$, et al. Regulation of NMDA receptor trafficking by amyloid-beta. Nat Neurosci 2005;8:1051-1058.

34. Nakajima A, Yamakuni T, Matsuzaki K, Nakata N, Onozuka $\mathrm{H}$, Yokosuka A, et al. Nobiletin, a citrus flavonoid, reverses learning impairment associated with $N$-methyl-D-aspartate receptor antagonism by activation of extracellular signalregulated kinase signaling. J Pharmacol Exp Ther 2007; 321:784-790

35. Cammarota M, Bevilaqua LR, Ardenghi P, Paratcha G, Levi de Stein M, Izquierdo I, et al. Learning-associated activation of nuclear MAPK, CREB and Elk-1, along with
Fos production, in the rat hippocampus after a one-trial avoidance learning: abolition by NMDA receptor blockade. Brain Res Mol Brain Res 2000;76:36-46.

36. Alonso $\mathrm{M}$, Viola $\mathrm{H}$, Izquierdo I, Medina JH. Aversive experiences are associated with a rapid and transient activation of ERKs in the rat hippocampus. Neurobiol Learn Mem 2002;77:119-124.

37. Sagare AP, Bell RD, Zlokovic BV. Neurovascular dysfunction and faulty amyloid $\beta$-peptide clearance in Alzheimer disease. Cold Spring Harb Perspect Med 2012;2. doi: 10.1101/cshperspect.a011452.

38. Wang X, Xing A, Xu C, Cai Q, Liu H, Li L. Cerebrovascular hypoperfusion induces spatial memory impairment, synaptic changes, and amyloid- $\beta$ oligomerization in rats. J Alzheimers Dis 2010;21:813-822.

39. Yamamoto Y, Shioda N, Han F, Moriguchi S, Nakajima A, Yokosuka A, et al. Nobiletin improves brain ischemiainduced learning and memory deficits through stimulation of CaMKII and CREB phosphorylation. Brain Res 2009; 1295:218-229.

40. Takeda T. Senescence-accelerated mouse (SAM) with special references to neurodegeneration models, SAMP8 and SAMP10 mice. Neurochem Res 2009;34:639-659.

41. Butterfield DA, Poon HF. The senescence-accelerated prone mouse (SAMP8): a model of age-related cognitive decline with relevance to alterations of the gene expression and protein abnormalities in Alzheimer's disease. Exp Gerontol 2005:40:774-783.

42. Tomobe K, Nomura Y. Neurochemistry, neuropathology, and heredity in SAMP8: a mouse model of senescence. Neurochem Res 2009;34:660-669.

43. Nakajima A, Aoyama Y, Nguyen TT, Shin EJ, Kim HC, Yamada S, et al. Nobiletin, a citrus flavonoid, ameliorates cognitive impairment, oxidative burden, and hyperphosphorylation of tau in senescence-accelerated mouse. Behav Brain Res 2013;250:351-360.

44. Phillips RG, LeDoux JE. Differential contribution of amygdala and hippocampus to cued and contextual fear conditioning. Behav Neurosci 1992;106:274-285.

45. Ohta A, Akiguchi I, Seriu N, Ohnishi K, Yagi H, Higuchi $\mathrm{K}$, et al. Deterioration in learning and memory of fear conditioning in response to context in aged SAMP8 mice. Neurobiol Aging 2001;22:479-484.

46. Sakurai T, Ogasawara J, Kizaki T, Ishibashi Y, Fujiwara T, Akagawa $\mathrm{K}$, et al. Involvement of leucine zipper transcription factor-like protein 1 (Lztfll) in the attenuation of cognitive impairment by exercise training. Biochem Biophys Res Commun 2011;416:125-129.

47. LaBar KS, Cabeza R. Cognitive neuroscience of emotional memory. Nat Rev Neurosci 2006;7:54-64.

48. Sartori SB, Hauschild M, Bunck M, Gaburro S, Landgraf R, Singewald N. Enhanced fear expression in a psychopathological mouse model of trait anxiety: pharmacological interventions. PLoS One 2011;6:e16849.

49. Markesbery WR. Oxidative stress hypothesis in Alzheimer's disease. Free Radic Biol Med 1997;23:134-147.

50. Nomura $Y$, Wang BX, Qi SB, Namba T, Kaneko S. Biochemical changes related to aging in the senescenceaccelerated mouse. Exp Gerontol 1989;24:49-55.

51. Butterfield DA, Howard BJ, Yatin S, Allen KL, Carney JM. Free radical oxidation of brain proteins in accelerated senescence and its modulation by N-tert-butyl-alphaphenylnitrone. Proc Natl Acad Sci U S A 1997;94:674-678.

52. Okatani Y, Wakatsuki A, Reiter RJ, Miyahara Y. Melatonin reduces oxidative damage of neural lipids and proteins in 
senescence-accelerated mouse. Neurobiol Aging 2002;23: 639-644.

53. Nemoto K, Ikeda A, Yoshida C, Kimura J, Mori J, Fujiwara $\mathrm{H}$, et al. Characteristics of nobiletin-mediated alteration of gene expression in cultured cell lines. Biochem Biophys Res Commun 2013;431:530-534.

54. Ikeda A, Nemoto K, Yoshida C, Miyata S, Mori J, Soejima $\mathrm{S}$, et al. Suppressive effect of nobiletin, a citrus polymethoxyflavonoid that downregulates thioredoxin-interacting protein expression, on tunicamycin-induced apoptosis in SK-N-SH human neuroblastoma cells. Neurosci Lett 2013; 549:135-139.

55. Su JD, Yen JH, Li S, Weng CY, Lin MH, Ho CT, et al. 3',4'-didemethylnobiletin induces phase II detoxification gene expression and modulates PI3K/Akt signaling in PC12 cells. Free Radic Biol Med 2012;52:126-141.

56. Lu YH, Su MY, Huang HY, Lin-Li, Yuan CG. Protective effects of the citrus flavanones to PC12 cells against cytotoxicity induced by hydrogen peroxide. Neurosci Lett 2010;484:6-11.

57. Goedert M, Spillantini MG. A century of Alzheimer's disease. Science 2006;314:777-781.

58. Bramblett GT, Goedert M, Jakes R, Merrick SE, Trojanowski JQ, Lee VM. Abnormal tau phosphorylation at Ser396 in Alzheimer's disease recapitulates development and contributes to reduced microtubule binding. Neuron 1993; 10:1089-1099.

59. Johnson GV, Stoothoff WH. Tau phosphorylation in neuronal cell function and dysfunction. J Cell Sci 2004;117: 5721-5729.

60. Han D, Qureshi HY, Lu Y, Paudel HK. Familial FTDP-17 missense mutations inhibit microtubule assembly-promoting activity of tau by increasing phosphorylation at Ser202 in vitro. J Biol Chem 2009;284:13422-13433.

61. Cho JH, Johnson GV. Primed phosphorylation of tau at Thr231 by glycogen synthase kinase 3beta (GSK3beta) plays a critical role in regulating tau's ability to bind and stabilize microtubules. J Neurochem 2004;88:349-358.

62. Goedert M, Jakes R, Crowther RA, Six J, Lübke U, Vandermeeren $\mathrm{M}$, et al. The abnormal phosphorylation of tau protein at Ser-202 in Alzheimer disease recapitulates phosphorylation during development. Proc Natl Acad Sci USA 1993;90:5066-5070.

63. Morishima-Kawashima M, Hasegawa M, Takio K, Suzuki M, Yoshida H, Titani K, et al. Proline-directed and non-proline-directed phosphorylation of PHF-tau. J Biol Chem 1995;270:823-829.

64. Rudrabhatla P, Jaffe H, Pant HC. Direct evidence of phosphorylated neuronal intermediate filament proteins in neurofibrillary tangles (NFTs): phosphoproteomics of Alzheimer's NFTS. FASEB J 2011;25:3896-3905.

65. Arriagada PV, Growdon JH, Hedley-Whyte ET, Hyman BT.
Neurofibrillary tangles but not senile plaques parallel duration and severity of Alzheimer's disease. Neurology 1992;42:631-639.

66. Berg L, McKeel DW Jr, Miller JP, Storandt M, Rubin EH, Morris JC, et al. Clinicopathologic studies in cognitively healthy aging and Alzheimer's disease: relation of histologic markers to dementia severity, age, sex, and apolipoprotein E genotype. Arch Neurol 1998;55:326-335.

67. Giannakopoulos P, Kövari E, Gold G, von Gunten A, Hof $\mathrm{PR}$, Bouras C. Pathological substrates of cognitive decline in Alzheimer's disease. Front Neurol Neurosci 2009;24:2029.

68. Cui Y, Wu J, Jung SC, Park DB, Maeng YH, Hong JY, et al. Anti-neuroinflammatory activity of nobiletin on suppression of microglial activation. Biol Pharm Bull 2010;33: 1814-1821.

69. Pardridge WM. Alzheimer's disease drug development and the problem of the blood-brain barrier. Alzheimers Dement 2009;5:427-432.

70. Saigusa D, Shibuya M, Jinno D, Yamakoshi H, Iwabuchi Y, Yokosuka A, et al. High-performance liquid chromatography with photodiode array detection for determination of nobiletin content in the brain and serum of mice administrated the natural compound. Anal Bioanal Chem 2011; 400:3635-3641.

71. Asakawa T, Hiza A, Nakayama M, Inai M, Oyama D, Koide $\mathrm{H}$, et al. PET imaging of nobiletin based on a practical total synthesis. Chem Commun (Camb) 2011;47:2868-2870.

72. Yasuda T, Yoshimura Y, Yabuki H, Nakazawa T, Ohsawa $\mathrm{K}$, Mimaki Y, et al. Urinary metabolites of nobiletin orally administered to rats. Chem Pharm Bull (Tokyo) 2003;51: 1426-1428.

73. Li S, Wang Z, Sang S, Huang MT, Ho CT. Identification of nobiletin metabolites in mouse urine. Mol Nutr Food Res 2006;50:291-299.

74. Al Rahim M, Nakajima A, Saigusa D, Tetsu N, Maruyama $\mathrm{Y}$, Shibuya $\mathrm{M}$, et al. 4'-Demethylnobiletin, a bioactive metabolite of nobiletin enhancing PKA/ERK/CREB signaling, rescues learning impairment associated with NMDA receptor antagonism via stimulation of the ERK cascade. Biochemistry 2009;48:7713-7721.

75. Lee J, Bogyo M. Target deconvolution techniques in modern phenotypic profiling. Curr Opin Chem Biol 2013;17:118126.

76. Futamura Y, Muroi M, Osada H. Target identification of small molecules based on chemical biology approaches. Mol Biosyst 2013;9:897-914.

77. Seki T, Kamiya T, Furukawa K, Azumi M, Ishizuka S, Takayama S, et al. Nobiletin-rich Citrus reticulata peels, a kampo medicine for Alzheimer's disease: a case series. Geriatr Gerontol Int 2013;13:236-238. 